\title{
Reversible myeloneuropathy and pancytopenia related to copper deficiency from gastric bypass surgery: A case report
}

\author{
Laide Bello, Joseph Fiore
}

\begin{abstract}
Introduction: Weight loss surgery has become an increasingly popular means of combating the obesity epidemic in modern society but like any procedure, it does not shy away from immediate and long-term complications. Copper deficiency has occasionally been reported to occur many years afterwards but with an increased incidence of bariatric procedures and reduced awareness, the effects of this deficiency could now appear to favor an earlier onset. Case Report: We report a case of a 56-year-old Caucasian female with a history of gastric bypass surgery five year ago; with an unsteady gait, weakness, decreased visual acuity, tingling with numbness in her hands and pancytopenia for the last month. She was treated for copper deficiency. Conclusion: Effects of copper deficiency have been shown to cause a wide array of abnormalities related to inactivation of enzymes such as cytochrome c oxidase, superoxide dismutase, dopamine beta hydroxylase and metallothionein. This can lead to reduced nerve transmission within the central nervous system causing motor and
\end{abstract}

Laide Bello ${ }^{1}$, Joseph Fiore ${ }^{2}$

Affiliations: ${ }^{1}$ Department of Medicine, Steward Carney Hospital, TUFTS University School of Medicine, Boston, MA, 2100 Dorchester Avenue, Boston, Massachusetts, USA; 2 Division of Gastroenterology, Seton Medical Office Building, Steward Carney Hospital, TUFTS University School of Medicine, Boston, MA 02124, 2110 Dorchester Avenue, Boston, Massachusetts, USA.

Corresponding Author: Laide Bello, MD, MPH, Department of Medicine, Steward Carney Hospital, TUFTS University School of Medicine, Boston, MA, 2100 Dorchester Avenue, Boston, Massachusetts, 02124.; Email: Laidebello@hotmail.com sensory polymyeloneuropathy and an overall reduction of energy required for blood cell formation. With early surveillance, such anomalies can be detected and potentially reverse the effects of this micronutrient deficiency.

Keywords: Myeloneuropathy, Hemoglobinopathy, Micronutrient deficiency

$$
* * * * * * * * *
$$

Bello L, Fiore J. Reversible myeloneuropathy and pancytopenia related to copper deficiency from gastric bypass surgery: A case report. International Journal of Case Reports and Images 2013;3(1):24-27.

$* * * * * * * * *$

doi:10.5348/ijcri-2013-01-252-CR-6

\section{INTRODUCTION}

Morbid obesity is one of the major risk factors associated with chronic diseases and conditions such as heart disease, cancer, stroke, diabetes and hypertension [1]. Given this impact on morbidity and mortality in the 21st century, weight loss surgery options are bound to be more prevalent than ever before and the Roux-en-Y gastric bypass remains the most common type done in the United States [2]. This procedure involves dividing the stomach into a small upper pouch and anastomosing it to a distal segment of the jejunum thus creating a gastro-jejunostomy for drainage of gastric remnant contents, bile and pancreatic enzymes. This bypass potentially eliminates common micronutrients such as iron, vitamin B12, calcium and vitamin D from being absorbed through the latter stomach and initial part of the small intestine [3-5]. There have been few reports of other complications such as copper deficiency which caused detrimental long-term outcomes such as 
myeloneuropathies, anemia, leucopenia and sometimes thrombocytopenia, but with early surveillance these conditions can be reversed $[6,7]$.

\section{CASE REPORT}

A 56-year-old Caucasian female presented to our emergency room with complains of unsteady gait, visual disturbance, dizziness, fatigue and recurrent tingling with numbness in her hands for the past month. She lost $68.03 \mathrm{~kg}$ ever since her gastric bypass surgery five years ago and more recently developed poor appetite, recurrent diarrhea and nausea despite being compliant with once daily iron, thiamine and folic acid supplements. Her gait had worsened to the point of requiring a cane for ambulation due to frequent falls. A recent upper endoscopy showed a gastro-jejunal anastomotic ulcer (H. Pylori negative) and colonoscopy revealed mild diverticulosis with several previous examinations in the past failing to show any clear cut etiology.

The past medical history of the patient was significant for depression and chronic hepatitis $\mathrm{C}$ (Genotype 2). She was a retired home care administrator, with no family history of gastrointestinal malignancy and routinely took pantoprazole, citalopram, calcium and vitamin D supplements.

On physical examination, patient appeared frail with a body mass index $17.5 \mathrm{~kg} / \mathrm{m}^{2}$ ( $84 \%$ of ideal body weight), blood pressure $124 / 84 \mathrm{mmHg}$, heart rate $90 / \mathrm{min}$ and respiratory rate $14 / \mathrm{min}$. Neurological review revealed reduced strength and sensation over her lower extremities, decreased ankle jerk, ataxic gait and moderate loss of vibratory and joint position sense in the toes. An ophthalmologic examination showed reduced visual acuity and protracted optic disc swelling. The rest of the physical examination was normal. Her laboratory examination was unique for a white blood cell count $2.2 \times 10^{3} / \mathrm{mm}^{3}$ (nadir $1.4 \times 10^{3} / \mathrm{mm}^{3}$ ), hemoglobin $8.9 \mathrm{~g} / \mathrm{dL}$, mean corpuscular volume (MCV) $72 \mathrm{fl}$ and platelet count $8.8 \times 10^{5} / \mathrm{mm}^{3}$. Her iron, percent saturation and vitamin B12 levels were preserved in a high normal range at $76 \mu \mathrm{g} / \mathrm{dL}, 40 \%$ and $652 \mathrm{pg} / \mathrm{mL}$, respectively. A hepatitis $\mathrm{C}$ viral load was undetectable while creatinine phosphokinase remained within normal limits. Serologies for lyme titer and syphilis were undetectable. A brain and entire spine magnetic resonance imaging was otherwise normal except for minimal T2 hyper-intensities within the periventricular white matter suggesting demyelination [8-10]. Her cerebrospinal fluid analysis was essentially unremarkable with no evidence of oligoclonal banding. An electroencephalogram recording revealed subtle slowing of the background suggestive of mild encephalopathy with no epileptiform activity and nerve conduction studies showed some motor and sensory polyneuropathy affecting different parts of her upper and lower extremities. At that juncture given her history of gastric bypass surgery, ongoing pancytopenia and complains of dizziness with unsteady gait, it was decided to assess for copper deficiency. This was seen low at $0.44 \mu \mathrm{g} / \mathrm{mL}$ (normal range $0.75-1.45 \mu \mathrm{g} / \mathrm{mL}$ ) along with zinc at $0.37 \mu \mathrm{g} / \mathrm{mL}$ (normal range $0.66-1.1 \mu \mathrm{g} / \mathrm{mL}$ ) but had a normal ceruloplasmin level. The 24 hour urine collection for copper was also low at $9 \mu \mathrm{g} / \mathrm{L}$ (normal range $15^{-60} \mu \mathrm{g} / \mathrm{L}$ ) and over the next three days she received a once daily intravenous infusion (containing 1 mg of copper) in dextrose water along with a high potency Women's Ultra Mega vitamin supplement four times a day. This contained $2 \mathrm{mg}$ of copper, several fat and water soluble vitamins as well as trace elements like manganese, chromium, selenium, magnesium and zinc. Over the next four to five days, her gait and vision improved remarkably with increased acuity and resolution of the optic disc swelling on examination. She no longer required any assistance with ambulation after a week, and was subsequently discharged on oral copper supplements. Table 1 gives her follow-up laboratory data after the first and second months. On subsequent follow ups in the out-patient clinic, the patient had shown great improvement with her overall strength and ambulation but still had some lingering but subtle tingling with numbness in the hands.

\section{DISCUSSION}

Copper remains an essential nutrient serving as a ceruloplasmin co-factor in the formation of transferring [11]. It thus facilitates iron uptake and ensures adequate red and white blood cell formation. Copper also plays a critical role in activating enzymes such as cytochrome c oxidase, superoxide dismutase, dopamine beta hydroxylase, metallothionein and its deficiency can lead to reduced nerve transmission within the central nervous system and less adenosine triphosphate production for synthesis of hemoglobin [5]. The actual

Table 1: Laboratory data compared from admission and one month later after copper supplementation

\begin{tabular}{llccc}
\hline & Normal Range & Initial Baseline & After one month & After two months \\
\hline Hemoglobin $(\mathrm{g} / \mathrm{dL})$ & $11-16$ & 8.9 & 10 & 11.8 \\
White cell count $\left(\mathrm{x} 10^{3} / \mathrm{mm}^{3}\right)$ & $4.5^{-11}$ & 2.2 & 4.8 & 6.4 \\
Platelets $\left(\mathrm{x} 10^{5} / \mathrm{mm}^{3}\right)$ & $150-400$ & 88 & 246 & 282 \\
Copper Level $(\mu \mathrm{g} / \mathrm{mL})$ & $0.75^{-1.45}$ & 0.44 & 0.71 & 0.79 \\
\hline
\end{tabular}


mechanism on how neutropenia occurs is still unknown, but Lazarchick et al. suggested an inhibition of differentiation and self-renewal of CD34 positive hematopoietic progenitor cells as a likely cause [12]. Most cases of copper deficiency myeloneuropathy typically occur after a few decades of gastric bypass surgery but in our patient the symptoms were seen only after a few years $[8,13]$. Shorter gastrointestinal tracts may cause reduced sites for reabsorption and a lack of micronutrient replacement can compound this deficiency. Zinc can interfere with copper metabolism since they compete for absorption via the same site and O'Donnell et al. advised against simultaneous supplementation in situations where both are found to be deficient [14]. Previous studies have linked hyperzincemia from toxic exposures as a potential cause of copper deficiency but this was not the case in our patient. With varying degrees of copper deficiency, patients may not necessarily have all the signs and symptoms listed and in order to make the diagnosis a clinician would need to have a high index of suspicion, along with demonstrable low copper levels. The occurrence of long-term irreversible neurological damage is not known and as such it is paramount to consider early surveillance. Kumar et al. have also studied the value of urinary copper as a measure of its deficiency but concluded that a serum copper level remains the best and most reliable assay [8]. An initial intravenous dose of $1 \mathrm{mg}$ of copper is advised for the first three days after which patients can continue on oral supplementation of $8 \mathrm{mg}$ of copper gluconate daily [15]. Our patient received these and blood levels for copper gradually normalized over the next two months along with other respective hematologic parameters. She did not require any blood transfusions during her stay and the abatement of her symptomatology was quite impressive over the immediate days to weeks of commencing therapy. In the absence of other causes for pancytopenia, blood levels usually improve or normalize anywhere within three days to six months after supplementation $[11,15-17]$. The actual threshold between copper concentrations, tissue stores and neurological sequelae remains to be established and more studies shall be required in the future to establish this. The myeloneuropathy described here can also mimic subacute combined degeneration typically seen with vitamin B12 deficiency, as such this should also be assessed and treated promptly. Even though serial levels of serum copper measured over time was seen to rise, potential confounding effects could exist with various vitamins and trace elements contained in the branded high potency Women's Ultra Mega vitamin supplement.

\section{CONCLUSION}

Early surveillance for copper deficiency has its benefits and ought to be routinely evaluated after a patient undergoes gastric bypass surgery as this gives the clinician an avenue to identify preventable and reversible causes of blood cell disorders, leukemic transformation and polyneuropahthies that would otherwise have been termed idiopathic.

$* * * * * * * * *$

\section{Author Contributions}

Laide Bello - Substantial contributions to conception and design, Analysis and interpretation of data, Drafting the article, revising it critically for important intellectual content, Final approval of the version to be published

Joseph Fiore - Substantial contributions to conception and design, Analysis and interpretation of data, Revising it critically for important intellectual content, Final approval of the version to be published

\section{Guarantor}

The corresponding author is the guarantor of submission.

\section{Conflict of Interest}

Authors declare no conflict of interest.

\section{Copyright}

(C) Laide Bello et al. 2013; This article is distributed under the terms of Creative Commons Attribution 3.0 License which permits unrestricted use, distribution and reproduction in any means provided the original authors and original publisher are properly credited. (Please see www.ijcasereportsandimages.com /copyright-policy.php for more information.)

\section{REFERENCES}

1. Health statistics, United States 2009. Retrieved from

http://www.cdc.gov/nchs/data/hus/huso9.pdf\#047

2. John S, Hoegerl C. Nutritional Deficiencies after gastric bypass surgery. Journal of American Osteopathic Association 2009;109(11):601-4.

3. Alvarez-Leite JI. Nutrient deficiencies secondary to bariatric surgery. Current Opinion in Clinical Nutritional Metabolic Care 2004;7(5):569-75.

4. Aills L, Blankenship J, Buffington C, Furtado M, Parrott J. ASMBS allied health nutritional guidelines for the surgical weight loss patient. Surgical Obesity Related Diseases 2008:4(5 Suppl):S73-108.

5. Linder MC, Hazegh-Azam M. Copper biochemistry and molecular biology. American Journal of Clinical Nutrition 1996;63(5):797S-811S.

6. Huff JD, Keung YK, Thakuri M, et al. Copper deficiency causes reversible myelodysplasia. American Journal of Hematology 2007;82(7):625-30.

7. Kumar N, Elliott MA, Hoyer JD, Harper CM Jr, Ahlskog JE, Phyliky RL. "Myelodysplasia," myeloneuropathy, and copper deficiency. Mayo Clinic Proceedings 2005;80(7):943-6.

8. Kumar N, Gross JB Jr, Ahlskog JE. Copper deficiency myelopathy produces a clinical picture like subacute combined degeneration. Neurology 2004;63(1):33-9. 
9. Spinazzi M, De Lazzari F, Tavolato B, Angelini C, Manara R, Armani M. Myelo-optico-neuropathy in copper deficiency occurring after partial gastrectomy. Do small bowel bacterial overgrowth syndrome and occult zinc ingestion tip the balance? Journal of Neurology 2007;254(8):1012-7.

10. Hedera P, Peltier A, Fink JK, Wilcock S, London Z, Brewer GJ. Myelopolyneuropathy and pancytopenia due to copper deficiency and high zinc levels of unknown origin II. The denture cream is a primary source of excessive zinc. Neurotoxicology 2009;30(6):996-9.

11. http://www.drugs.com. Copper information from Drugs.com; [Revised: 08/2011 Hospira, Inc.; Cited: 2012 March 4]. Available from: http://www.drugs.com/pro/copper.html.

12. Lazarchick J. Update on anemia and neutropenia in copper deficiency. Current Opinion on Hematology 2012 Jan;19(1):58-60.

13. Wu J, Ricker M, Muench J. Copper deficiency as cause of unexplained hematologic and neurologic deficits in patient with prior gastrointestinal surgery. Journal of American Board of Family Medicine 2006;19(2):191-4.

14. O'Donnell KB, Simmons M. Early-Onset Copper Deficiency Following Roux-en-Y Gastric Bypass. Nutrition in Clinical Practice 2011;26(1):66-9.

15. Shahidzadeh R, Sridhar S. Profound copper deficiency in a patient with gastric bypass. American Journal of Gastroenterology 2008;103(10):2660-2.

16. Griffith DP, Liff DA, Ziegler TR, Esper GJ, Winton EF. Acquired copper deficiency: a potentially serious and preventable complication following gastric bypass surgery. Obesity (Silver Spring) 2009;17(4):827-31.

17. Kelkar P, Chang S, Muley SA. Response to oral copper supplementation in copper deficiency myeloneuropathy. Journal of Clinical Neuromuscular Disease 2008;10(1):1-3.
Access full text article on other devices

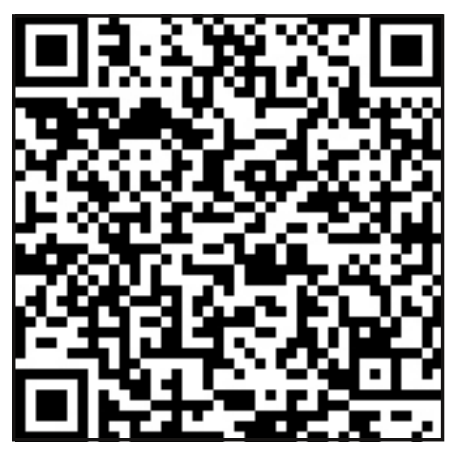

Access PDF of article on other devices

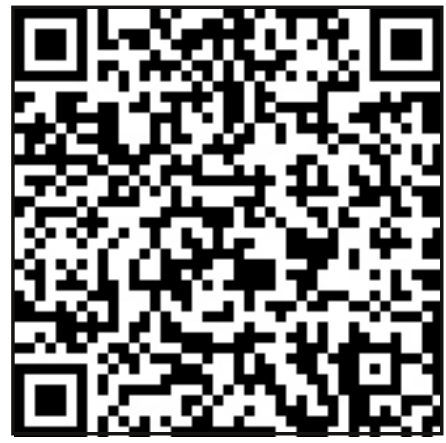

